INTERNATIONAL HIGHER EDUCATION Number 74 Winter 2014

Pages 10-11

\title{
Can the Great American Universities Take Root in Asia?
}

HARRY LEWIS

Harry Lewis is professor of computer science at Harvard and former dean of Harvard College. E-mail: lewis@seas.harvard.edu. This article appeared in the South China Morning Post, on August 5, 2013.

The news that the University of Chicago Booth Business School's executive master of business administration program would relocate from Singapore was greeted in Hong Kong, with as much enthusiasm as the acquisition of a star athlete. Education Secretary Eddie Ng Hak-kim trumpeted that the move would “enhance Hong Kong's position as a regional education hub, nurture talent to support the growth of our economy, and strengthen Hong Kong's competitiveness."

But the ongoing changes in higher education are more like biological evolution than a cricket match. Extinction too is part of evolution-and several other American outposts in Singapore, including New York University's Tisch School of the Arts and the hotel school of University of Nevada, Las Vegas, are pulling out of the city state with uncertain future plans.

Asia is trying to shortcut a process that took centuries to create the great American universities. And American universities seem to think that an 
intellectual Bering land bridge has opened. Suddenly, they see huge areas with no natural competitors, a promising ecosystem for invasive species.

For a university giving up the right to political expression means giving up the pursuit of the truth. This is vanity on both sides, I expect. I wonder how we will think about today's higher education innovations a few decades from now. Perhaps some of the new institutions will prove to be failed experiments, mutations that proved not to fit the environmental niche. The Singapore government was unwilling to keep subsidizing the University of Nevada, Las Vegas, for example, and a joint Singaporean venture with New York University School of Law is closing after spending down its sizable government subsidy.

All is guesswork and experimentation. Will any of these American transplants survive for even a decade? If they survive for the century, will they and their venerable American cousins have become strangers to each other, like the snapping shrimp, that no longer recognize each other as relatives because the rising Isthmus of Panama separated them into Caribbean and Pacific species?

If it is too expensive for universities to do business in Singapore-and the strength of the Singapore dollar is part of the story—how will they do in Hong Kong? That may depend on the willingness of Hong Kong to continue the kinds of subsidies that drew the Chicago Business School. Hong Kong is charging Chicago a mere $\mathrm{HK} \$ 1,000$ for a 10 -year lease on old officers' quarters on Hong Kong Island. I hope Hong Kong's own universities, themselves products of a continuing evolutionary process, are treated equally well. The University of Chicago is surely grateful to the people of Hong Kong for making its very profitable business program even more lucrative. 
There is a risk that Hong Kong, like Singapore, will find these subsidies unsustainable. Perhaps the government should wait a few years before celebrating its triumph. As a Singaporean official said: "If a branded school is unable to persuade its students to pay their market fees, then it suggests that the brand may not be so attractive after all."

The cream of the crop of academic exotics in Asia is the Yale-National University of Singapore campus, set to open soon. Will the environment be rich enough-in Singaporean and American funds, and Asian students-to keep it alive? So far, none of the closures seems to be related to issues that deeply concern the Yale faculty: how to teach in the spirit of open inquiry in a place where one can be jailed for criticizing the government (or for homosexuality, or a variety of other things unconstrained in American universities).

At some point, American universities venturing into authoritarian states will have to square their ambitions with the values of their host countries. New York University president John Sexton's statement about his university's Shanghai campus won't wash forever: "I have no trouble distinguishing between rights of academic freedom and rights of political expression."

Tell that to the students of the Hopkins-Nanjing Center, who thought they would be able to publish a magazine with an article about student protests, just as they could have done at Johns Hopkins University or anywhere else in the United States. The article was censored, and the magazine was put in limbo.

John Sexton is wrong. Anything can be political, not just the liberal arts but also the professional practice of business or law. For a university in which 
students can expect to study social issues of any kind, giving up the right to political expression means giving up the pursuit of the truth.

The large flows of money through academia and the hunger for higher education in Asia cannot obscure the reality that American higher education evolved in a climate of uncompromising commitment to freedom of thought and freedom of speech. This ecology should be Hong Kong's greatest advantage as a higher education hub.

Cultures that do not honor those values among their citizens will not be enduring hosts to American higher education-unless the American universities betray the very values that made them great. 